\title{
ADVERTISING ON THE MEDICAL TERMINOLOGY TEXTS IN RUSSIAN LANGUAGE AND ITS ANALYSIS
}

\author{
Aripova Xalima Aripovna \\ Associate Professor of Russian Language and Literature department Bukhara State University
}

\begin{abstract}
Аннотация
The article provides an overview of medical terminology and ideas on the role of medical terminology in advertising texts. In addition, the role of medical terminology in Russian advertising texts was analyzed using examples.
\end{abstract}

Ключевые слова: medical terminology, advertising texts, medical advertising, radio advertising, medical products, advertising discourse

\section{Introduction}

Within the framework of mass communication, a whole complex of certain texts functions with a special structure, a system of genres, and a linguistic appearance. With the change in socio- political guidelines from the late 80s - early 90s. XX century in Russia, the rapid growth of various types of advertising begins. It is safe to say that the advertising text as a special form of communicative exchange today occupies a large place in the system of mass communication. At the same time, we have to admit that not all aspects of the formation of advertising discourse and not all areas of advertising have been studied sufficiently and at a level that meets the scientific-theoretical, scientific-practical and applied needs of today's reality. In particular, this statement is true for the discourse of medical advertising. The problem of its consideration is of great interest, since it, to the greatest extent, than in other texts of mass communication, is connected with the issue of the specifics of medical newspaper and radio advertising.

The relevance of this study is determined by the degree of involvement of the advertising text in the life of modern society and, accordingly, the need for a deeper and more comprehensive study of the nature of this phenomenon, the mechanisms of its impact on the consciousness and behavior of the addressee. The study of advertising discourse, especially in the field of medicines, devices, services, has not only scientific, but also great social significance. At the same time, the issue of the humanization of advertising communication is acutely raised, since modern advertising of medical products by its obsession, psychological pressure on the addressee causes its rejection among a significant part of recipients.

\section{Literature review}

Among the works of domestic researchers, it is necessary to highlight the classic works of T.M. Dridze, A.A. Leontiev and the works of modern researchers of communication M.M. Nazarov, G.G. Pocheptsova and others. Of the most informative and interesting works on the theory of advertising communication and methods of influencing the audience, we note the works of I.V. Aleshina, G.G. Pocheptsov, L.N. Fedotova, works of foreign authors K.L. Bove, A. Deyan, G. Carter, F. Kotler and others.

The object of the research is the discourse of advertising of medical products (drugs, dietary supplements), which results in printed texts of newspaper advertisements and speech works of radio advertising in this area. 
The subject of the research is the linguo-pragmatic organization of medical advertising discourse.

The purpose of this work is to identify the features of the texts of commercial medical advertising from the point of view of linguistic pragmatics, to determine the ways of speech influence in the advertising discourse of medical topics.

The study of the language of the advertising text will also make it possible to clarify some concepts of modern linguistics related to the analysis of discourse, the problems of language manipulation (i.e. language as a socially powerful means of imposing views).

\section{Analysis}

In accordance with the indicated range of problems, the following tasks are solved:

1. Set the parameters of medical advertising discourse, analyze its specifics, identify the difference from other types of advertising discourse.

2. To characterize the linguistic ways of implementing speech strategies (the choice of linguistic means, the structure of speech impact).

3. Identify and trace the presence (or absence) of the evolution of advertising discourse of a medical nature and determine its nature (humanization? Dehumanization?).

4. Compare the pragmatic attitude of commercial and social medical advertising and the resulting language differences.

5. Carry out a survey of different (by age, gender, profession, education level) population groups in order to establish the effectiveness of medical advertising.

The solution of the tasks set allows us to put forward the following provisions for defense:

1. In the texts of newspaper medical and radio advertising, the primary role is played by their compositional-content and speech structure, syntactic representation, since, firstly, it allows you to clearly structure the advertising text, which favorably affects the advertising text itself, and secondly, thanks to these structures, it is possible to increase the impact of advertising discourse on the reader and radio listener.

2. For the implementation of a number of speech tactics of medical advertising, it is very important to use verbs of certain lexico-semantic groups.

3. Destructive verbs change their meaning in the context of medical advertising to a constructive one, which corresponds to the pragmatic attitudes of medical advertising. There is a counter process of changing the axiological semantics of the verbs of creation, improving the quality of being to the opposite - destructive.

4. A very significant role in the creation of an effective advertising discourse of a medical nature is played by the nominal parts of speech: abstract nouns and adjectives, qualitative and relative.

5. Recently, we can state an increase in the trend towards a variety of forms of discursive textual organization of advertising, both newspaper and radio advertising of medical products, which is due to the desire to humanize the advertising discourse.

In the fact that it provides a characteristic of advertising discourse and the texts generated by it within the framework of the theory of discourse analysis, in functional, linguo-social aspects; for the first time, a method for modeling the compositional-content structure of discourse in relation to advertising of medical goods was developed and implemented, a typology of its thematic components and their blocks was built, their role in the speech design of this type of discourse was revealed; interesting language material has been introduced into scientific use. 
The article is based on the method of complex linguistic description, including the techniques of observation, generalization, interpretation and classification, as well as the method comparison of newspaper and radio advertisements of health products, the method of questioning, in part - the quantitative-statistical method. Taking this circumstance into account, an attempt is made in this work to analyze the texts of medical advertising. The theoretical aspect of studying this issue is important because it is in line with such popular areas as sociolinguistic and pragmalinguistic studies of mass communication texts, and in line with linguistic research itself. The theoretical value of the research lies in the understanding of the complex, multidimensional phenomenon of advertising from a linguistic standpoint.

An attempt at a detailed analysis of this type of advertising discourse is presented, carried out on the basis of the application of the method of structuring its content, implemented from the position of the pragmatic attitudes of the addressee, which contributes to the development of a general theory of pragmatics, discourse analysis, since any general theory develops on the basis of those facts that are discovered through private research. Language analysis of advertising discourse presents great interest for linguistics, enriches knowledge about the functional nature of language in general, as well as about the patterns of it's functioning in one of the areas of activity.

Each advertising text of a medical nature, which is the object of this work, meets the criteria for textual content, highlighted in linguistic literature. These are advertising texts recorded in writing and sounding on the radio, consisting of a certain set of sentences determined by the pragmatic organization of the advertising discourse. The advertising text is characterized by compositional content and structural speech completeness and has a special specificity of expressing the author's attitude to the reported, namely: the presentation of the advertising object in the most favorable form for the advertiser. Thus, each medical advertisement in KP and radio advertisements of a medical nature is texts formed in the process of discourse, and, therefore, are subject to scientific analysis from the point of view of text linguistics. A review of the existing literature on advertising has convinced us that we should look for ways to analyze advertising for medical products that meet its subject specificity, namely, that such advertising is based on the sphere of human health. The denotative subject space of medical advertising is actually associated with the dominant of being / non-being of a person, i.e. the quality of his being (improving his being with the help of drugs).

\section{Discussion}

The entire compositional and content structure of medical advertising is built on the basis of the linguistic pragmatic use of the space between these opposed points in the mind of the recipient.

In the discourse of medical advertising justifying a health problem requires much more art, both rhetorical and psychological, than in other types of advertising. In this case, the "developments" of advertising of other subject areas of consumption are far from always suitable for advertising health products. On the other hand, the specificity of medical advertising discourse lies in the fact that in the sphere of human vital interests, this discourse has points of contact with the communicative interaction of a doctor and a patient, which, in our opinion, also affects the formation of the considered type of advertising communication, while this factor does not influences the creation of advertisements affecting other areas of human life space. This side of the life of a person, in essence, is exploited by advertising of medicines, albeit in a veiled way. It is this incentive to create medical advertising that determines its specificity, its difference from advertising associated with any other subject area of human life. The success of medical advertising requires a much deeper and more subtle penetration into the psyche of the human personality, taking into account its characteristics in comparison with other objects of advertising. In modern science, the main stages of the formation of medical terminology itself have been thoroughly studied, the lexical and semantic features of medical products have been investigated, methodological approaches to the study of medical 
terminology have been described, and the functional features of a medical text have been analyzed. The situation of communication in newspaper and radio advertising texts of a medical nature is realized in speech tactics, which are understood as speech techniques that make it possible to achieve the set goals in a specific situation, which serve as milestones in achieving the general goal in the strategy of the addresser-advertiser - to induce the addressee to become a consumer of the advertised medical products by influencing his consciousness in the right direction. The speech tactics of the doctor in the process of his communication with the patient pursue different goals.

The main goal of a doctor's cognitive strategies is to correct (in some cases change) the picture of the world of a potential patient, aimed at solving specific problems associated with the process of treating a particular disease.

The doctor-patient conversation and the discourse of medical advertising (i.e. advertising of health products) have some points of contact in the strategy and tactics of their implementation, but they are dictated by different pragmatic attitudes.

The desire to psychologically influence a potential buyer in order to create an atmosphere of trust, the illusion of proximity of the addressee to the authors of advertising or (in radio advertising) speech distributors, its voices is also dictated by the goal of convincing potential consumers of the proposed product to purchase it. At the same time, the addressee of the advertisement seeks to appear before the addressee in the role of his advisor, responding to the requests of one or another recipient (newspaper reader, radio listener) who wants to help solve this or that health problem. Hence the technique "the reader (radio listener) asks (writes, asks for advice)", typical in newspaper advertising of medical products and under its influence, we believe, has recently gained great popularity in radio advertising of drugs, medications, medical devices, dietary supplements.

As you can see, this technique has something in common in its communicative-speech form with the situation "patient's questions - doctor's answers" in a conversation between a doctor and a patient. However, in the latter case, this aspect of communicative interaction is natural, and it is really initiated by the patient, as an interested person. At the same time, the doctor who is obliged to take care of the patient's health is also interested in communicating information.

\section{Conclusion}

Thus, in this case, the dialogue built on the principle of "question - answer" is not an artificial discursive device, as is the case in medical advertising discourse. The difference in the pragmatic attitudes of these two different types of discourse - a doctor-patient conversation and medical advertising discourse - also led to a mismatch in a number of speech tactics in both. For example, the tactics of encouraging a patient who diligently fulfills medical prescriptions is absent in advertising communication, but the latter uses techniques that are not in the "doctor-patient" discourse. For example, such is the promise of discounts to customers, bonuses, promotions to reduce prices at a certain hour or on a holiday.

\section{References:}

1. Newspaper "Komsomolskaya Pravda" (KP)

2. Recordings of radio advertisements for medical products on the radio channel "Russia" for 2007-2012. (RT)

3. Television advertisements (TA)

4. Dictionaries and grammar reference books

5. Akhmanova O.S. Dictionary of linguistic terms / OS Akhmanova -M .: Publishing house "Soviet encyclopedia", 1966.- 608p. 
6. Babenko L.G. Comprehensive explanatory dictionary of Russian verbs. -M. AST-Press book, 2007.576p.

7. Great Soviet Encyclopedia / Great Soviet M .: Publishing House "Soviet Encyclopedia", 1975.

8. Big explanatory dictionary of the Russian language / Comp. and ch. ed. Kuznetsov S.A. /

9. S.A. Kuznetsov comp. and ch. ed. - SPb .: Norint, 1998 .-1536p.

10. A short dictionary of modern concepts and terms. 3rd ed. finished. and additional / N.T. Bukimovich, G.G. Zharkova, T.M. Kornilov and others - M .: Republic, 2000 . 670p.

11. Kubryakova E.S., Demyankov V.Z., Pankrats Yu.S., Luzina L.G. A Concise Dictionary of Cognitive Terms. Moscow: Moscow State University, 1996.

12. Linguistic encyclopedic dictionary / under the general. Ed. Yartsevoy V.M. M .: Sov. Encyclopedia, 1990 . -685p.

13. Lopatin V.V., Lopatin L.E. Russian explanatory dictionary. 4th ed. -M .: Russian language, $1997 .-832 p$.

14. The latest dictionary of foreign words and expressions M .: Contemporary writer, 2003. 976p.

15. Ozhegov S.I. Explanatory dictionary of the Russian language / S.I. Ozhegov, N.Y.Shvedova M.T994. - 928p.

16. Akaeva E.V. Communicative strategies of professional medical discourse: Author's abstract. dis. Cand. philol. sciences. Omsk, 2007.-- 25 p.

17. Actual problems of applied linguistics: a collection of materials of the First All-Russian Scientific and Practical Conference. Penza: PGSKhA, 2003.-220p.

18. http://cheloveknauka.com/lingvopragmatika-meditsinskogo-reklamnogodiskursa\#ixzz6sIXTH8Yf 